\title{
Significance of urinary hippuric acid determination as an index of toluene exposure
}

MASAYUKI IKEDA and HATSUE OHTSUJI

Department of Public Health, Kyoto University Faculty of Medicine, Kyoto, Japan

Ikeda, Masayuki, and Ohtsuji, Hatsue (1969). Brit. J. industr. Med., 26, 244-246. Significance of urinary hippuric acid determination as an index of toluene exposure. Urine samples from 118 male workers in photogravure printing factories were analysed for hippuric acid. The urinary levels of hippuric acid were proportional to the environmental concentrations of toluene, although within wide variations. The urinary concentration of hippuric acid corresponding to 200 p.p.m. of toluene was $3.5 \mathrm{~g}$./litre (specific gravity 1.016 ) or $4.3 \mathrm{~g}$./g. creatinine.

It is well known that when toluene is inhaled and absorbed it is mostly converted into hippuric acid (El Masry, Smith, and Williams, 1956). Recently, Ogata, Nagao, and Tomokuni (1968) exposed volunteers once to toluene in an experimental exposure chamber and showed that a quantitative correlation held between the environmental toluene concentrations and the amounts of hippuric acid excreted in urine. Pagnotto and Lieberman (1967) also reported this correlation. Based on those findings, a field survey has been conducted on factory workers who are exposed to toluene every day in their workshops to investigate if it is practicable to estimate the environmental toluene con-

TABLE

Hippuric Acid Concentration in Urine Samples from Workers Exposed Daily to Toluene at VARIOUS CONCENTRATIONS

\begin{tabular}{|c|c|c|c|c|c|}
\hline \multirow{3}{*}{ Workshops } & \multirow{3}{*}{$\begin{array}{c}\text { Toluene } \\
\text { concentrations } \\
\text { (p.p.m.) }\end{array}$} & \multirow{3}{*}{$\begin{array}{l}\text { No. of } \\
\text { workers }\end{array}$} & \multicolumn{3}{|c|}{ Hippuric acid concentrations ${ }^{1}$} \\
\hline & & & \multirow{2}{*}{$\begin{array}{c}\text { Observed values } \\
(\text { g./litre })\end{array}$} & \multicolumn{2}{|c|}{ Values corrected for } \\
\hline & & & & $\begin{array}{c}\text { Specific gravity } \\
(\text { g./litre })\end{array}$ & $\begin{array}{c}\text { Creatinine }^{3} \\
(\text { g. } / g .)\end{array}$ \\
\hline $\begin{array}{l}\mathbf{A} \\
\mathbf{B} \\
\mathbf{C} \\
\mathbf{D} \\
\mathbf{E} \\
\mathbf{F} \\
\mathbf{G} \\
\mathbf{H} \\
\mathbf{I} \\
\mathbf{J} \\
\mathbf{K}\end{array}$ & $\begin{array}{r}04 \\
4 \\
18 \\
20 \\
50 \\
60 \\
65 \\
80 \\
125 \\
180 \\
200 \\
240\end{array}$ & $\begin{array}{r}31 \\
8 \\
5 \\
10 \\
9 \\
10 \\
6 \\
8 \\
8 \\
22 \\
20 \\
12\end{array}$ & 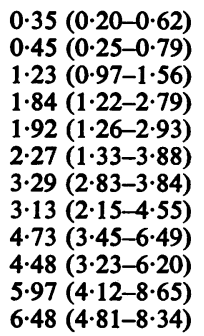 & $\begin{array}{l}0.29(0.16-0.51) \\
0.49(0.28-0.86) \\
0.90(0.60-1.24) \\
1.18(0.85-1.64) \\
1.40(1.03-1.89) \\
1.21(0.70-2.10) \\
1.87(1.62-2.16) \\
1.87(1.33-2.63) \\
2.84(2.28-3.54) \\
3.31(2.60-4.22) \\
3.66(2.62-5.11) \\
3.59(2.82-4.57)\end{array}$ & $\begin{array}{l}0.24(0.14-0.41) \\
0.43(0.36-0.53) \\
1.23(0.72-2.11) \\
1.06(0.81-1.40) \\
1.96(1.53-2.50) \\
1.14(0.75-1.72) \\
1.51(1.15-1.99) \\
1.64(1.05-2.55) \\
3.17(2.34-4.31) \\
4.21(3.42-5.19) \\
3.58(2.28-5.61) \\
5.67(4.38-7.34)\end{array}$ \\
\hline
\end{tabular}

${ }^{1}$ Geometric means with S.D. ranges in parentheses. ${ }^{2}$ Adjusted to a specific gravity of $1 \cdot 016$.
${ }^{3}$ Hippuric acid concentration divided by creatinine concentration. 4Values reported by Ikeda and Ohtsuji (1969). 
centration from the level of hippuric acid in the urine. Normal levels of hippuric acid in the urine of non-exposed Japanese subjects have already been reported (Ikeda and Ohtsuji, 1969).

\section{Materials and methods}

\section{Urine samples}

Urine samples, 118 in all, were collected from workers at 11 workshops in eight factories operating polychromic rotary presses for photogravure printing. This type of workshop was chosen as the press was run continuously in a closed room in which toluene was vaporized from several places, so that the toluene concentrations in these workshops were fairly constant. Urine was passed at about 1 p.m. and the urine samples for analysis were collected around 3 p.m., when the urinary levels of hippuric acid were expected to be highest (Ogata et al., 1968).

\section{Urinalyses}

Determination of both hippuric acid and creatinine was conducted as previously described (Ikeda and Ohtsuji, 1969). Results were adjusted in some instances to a specific gravity of urine of $1 \cdot 016$, as described by Elkins and Pagnotto (1965).

Determination of toluene concentration in air

Kitagawa detection tubes were used for this purpose. At least six determinations were made at various sites in each workshop and the average was taken to represent the environmental concentration of toluene. The maximum and minimum values differed from the mean by less than $30 \%$ of the mean.

\section{Statistical analyses}

Fiducial limit ranges were calculated on the assumption that a log-normal distribution would be applicable (Heath, 1967). Regression lines were calculated with weighting for the numbers of samples (Snedecor, 1956).

\section{Results and discussion}

Geometric means and S.D. ranges of hippuric acid levels in urine samples from workers in different workshops are listed in the Table. Correction of hippuric acid level for either specific gravity or creatinine concentration did not reduce the variation significantly, in agreement with a previous report (Ikeda and Ohtsuji, 1969). When the mean values in the Table were plotted against toluene concentration, they appeared to be well represented by a straight regression line (Figure). Both the S.D. ranges and the fiducial $(P=0.05)$ ranges increased at higher concentrations. The hippuric acid concentration corresponding to the atmospheric toluene concentration of 200 p.p.m., which is the maximal allowable concentration recommended by the Japanese Association of Industrial Health in 1968 and also the A.C.G.I.H. threshold limit value for 1967 , was estimated to be $3.5 \mathrm{~g}$./litre (specific gravity

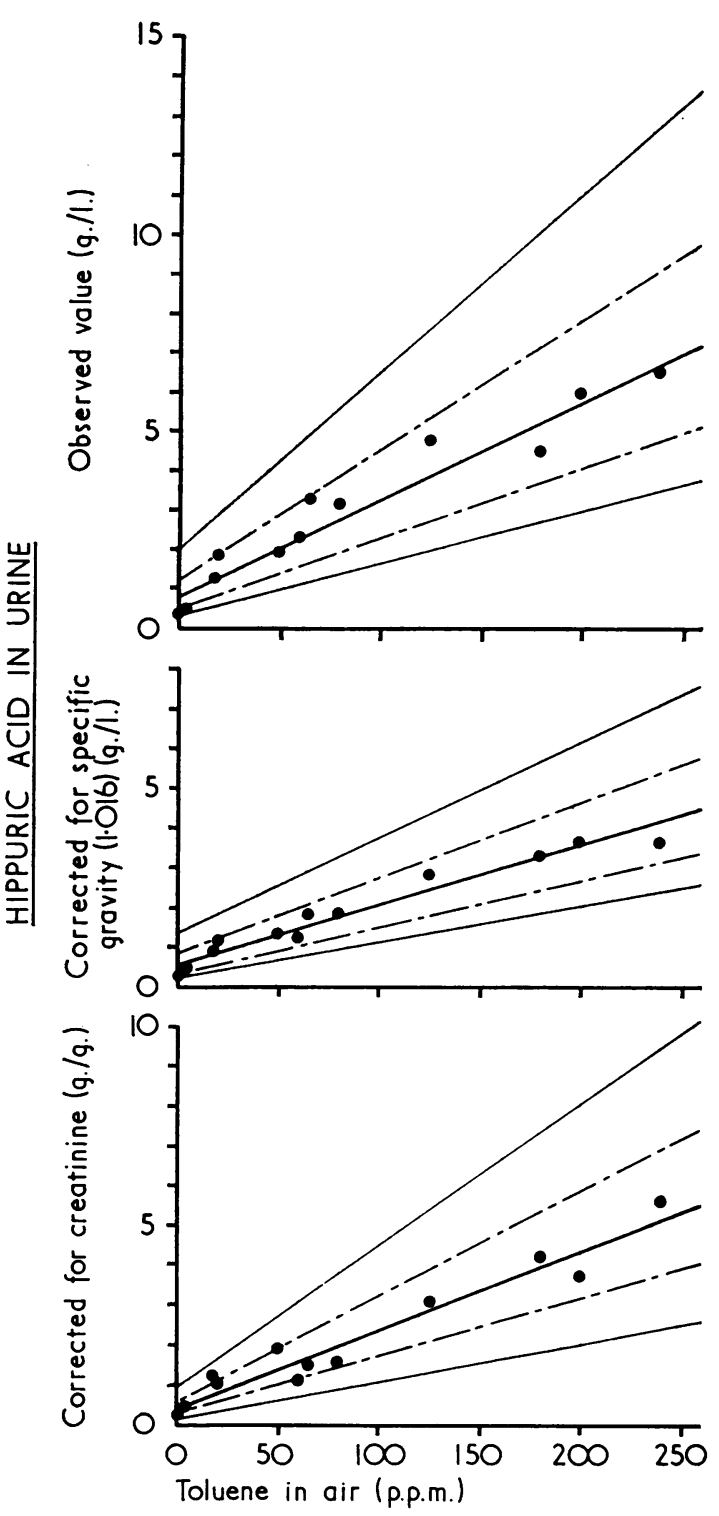

Figure. Mean values listed in the table (O). The lines are weighed calculated regression lines for the means (-) together with those for the S.D. ranges $\left(---_{-}\right)$and fiducial ranges $(P=0.05)(-)$.

$1.016)$ or $4.3 \mathrm{~g} . / \mathrm{g}$. creatinine. This value was roughly equal to Ogata's observation of $4.0 \mathrm{~g}$./litre with a single exposure (Ogata et al., 1968) (adjusted by the present authors to a specific gravity of $1 \cdot 016)$. The agreement of these two values appeared to show that repeated exposure to toluene, as described in this paper, did not significantly modify the metabolic fate of toluene. 
In many workshops using toluene, the environmental toluene concentration fluctuates markedly. For example, when metal parts are painted with a paint spray gun, the toluene concentration in air varies, depending on the operation of the spray gun and its intermittence as well as on the efficiency of an exhaust. In such a case it may be convenient if one can estimate the average concentration of toluene vapour inhaled, by determination of the hippuric acid level in the urine of the worker rather than by continuous determination of toluene in air. The linear regression line in the Figure seems to suggest this possibility. The range of variation in hippuric acid level is wide (see Figure) and it is difficult to make an accurate estimation of the atmospheric toluene concentration from the urinary level of hippuric acid. Nevertheless it is possible to separate those exposed to 200 p.p.m. of toluene from nonexposed subjects. At toluene concentrations higher than 100-130 p.p.m., the lower limit of the fiducial $(P=0.05)$ range is higher than the upper limit of the fiducial $(P=0.05)$ range for the non-exposed (Figure). Individual differences in toluene metabolism and fluctuations of environmental toluene concentrations in the workshops surveyed are among the possible causes of the wide variation. Further studies are to be conducted with the object of reducing the variation.

Thanks are due to Dr. S. Inui, of Kyoto Institute of Industrial Medicine, Dr. H. Watanabe, of Osaka City Institute of Hygiene, and their associates for their collaboration in collecting urine samples.

\section{References}

El Masry, A. M., Smith, J. N., and Williams, R. T. (1956). Studies in detoxication. 69. The metabolism of alkylbenzenes: n-propylbenzene and $n$-butylbenzene with further observations on ethylbenzene. Biochem. J., 64, 50-56.

Elkins, H. B., and Pagnotto, L. D. (1965). Is the 24-hour urine sample a fallacy? Amer. industr. Hyg. Ass. J., 26, 456-460.

Heath, D. F. (1967). Normal or log-normal: Appropriate distributions. Nature (Lond.), 213, 1159-1160.

Ikeda, M., and Ohtsuji, H. (1969). Hippuric acid, phenol and trichloracetic acid levels in the urine of Japanese subjects with no known exposure to organic solvents. Brit. J. industr. Med., 26, 162-164.

Ogata, M., Nagao, I., and Tomokuni, K. (1968). Urinary hippuric acid excretion in persons exposed to various concentrations of toluene in an exposure chamber. Jap. J. industr. Hlth, 10, 64-74. (in Japanese).

Pagnotto, L. D., and Lieberman, L. M. (1967). Urinary hippuric acid excretion as an index of toluene exposure. Amer. industr. Hyg. Ass., J., 28, 129-134.

Snedecor, G. W. (1956). Statistical Methods, 5th ed. Iowa State University Press, Ames, Iowa.

Received for publication November 29, 1968. 